\title{
"When you make manager, we put a big mountain in front of you": An ethnography of managers in a Big 4 Accounting Firm
}

\author{
Martin Kornberger ${ }^{\mathrm{a}, \mathrm{b}, *}$, Lise Justesen ${ }^{\mathrm{b}}$, Jan Mouritsen ${ }^{\mathrm{b}}$ \\ ${ }^{a}$ University of Technology, Sydney, Australia

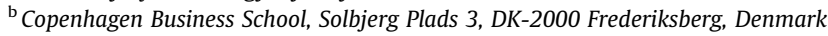

Previous studies of the socialization of trainee accountants put emphasis on how disciplin-ary power mechanisms shape their professional identities. Literature on the ongoing growth and commercialization of the Big 4 Accounting Firms suggests that senior employ-ees, and especially partners, have to be understood as entrepreneurially minded agents. These two bodies of knowledge provide the theoretical vantage point for our empirical analysis of the "missing link" between trainee and partner - the manager. Based on an ethnographic study of a Big 4 Firm (pseudonym Sky Accounting), we suggest understanding the career step of the manager as a rite of passage that has two effects: first, managers experience that their previous identity is destabilized; and second, our study shows how a set of new practices (performing, playing games and politicking) shape the identity of managers, enabling them to navigate the complex organizational network of a Big 4 Firm. We conclude our paper with a discussion of power effects of the rite of passage, how it shapes the identity of managers, and the practice of managerial work in a Big 4 Accounting Firm.

\section{Introduction}

This paper addresses the following research question: how can we understand the organizational space between trainees and partners in large accounting firms? Hierarchically, the manager occupies the space between the trainee and the partner. In existing literature, the manager seems to be a neglected species. While previous studies of accounting firms have shown how junior staff members are socialized and disciplined into professional accountants (e.g. Anderson-Gough, Grey, \& Robson, 2001; Coffey, 1994; Grey, 1998), other scholars have focused on the identity of partners (e.g. Covaleski, Dirsmith, Heian, \& Samuel, 1998; Dirsmith \& Covaleski, 1985). Following these accounts of careers, socialization and the formation of professional

\footnotetext{
* Corresponding author at: Faculty of Business, University of Technology, Sydney, PO Box 123, Broadway NSW 2007, Australia. Tel.: +61 29514 3613; fax: +61295143602.

E-mail address: martin.kornberger@uts.edu.au (M. Kornberger).
}

identity, studying the identity of managers and analyzing how they make sense of their journey from junior trainees to potential partners is an important yet overlooked topic. As our empirical narrative will illustrate, managers experience a fundamental transition, which we analyze as a rite of passage (Bourdieu, 1991; Turner, 1967; van Gennep, 1960). In this rite of passage, the world of junior accountants is deconstructed and newly promoted managers learn to brace themselves for the complexities that constitute the organizational realities of a Big 4 Accounting Firm.

This paper aims to make a theoretical and an empirical contribution to accounting studies. First, this paper contributes with a rich ethnographic analysis of the space of the manager in a Big 4 Firm to the growing body of accounting firm ethnographies that have emerged in the fields of accounting, organization studies and the sociology of the professions (Anderson-Gough et al., 2001; Anderson-Gough, Grey, \& Robson, 2005; Coffey, 1994; Covaleski et al., 1998; Dirsmith, Heian, \& Covaleski, 1997; Grey, 1994, 1998; Kornberger, Carter, \& Ross-Smith, 
2010; Pentland, 1993). The paper complements these critical studies on the early socialization of trainees (e.g. Anderson-Gough et al., 2001; Coffey, 1994; Grey, 1994) and the work on identities of partners (e.g. Covaleski et al., 1998) by analyzing the "missing link" between trainees and partners - managers. Our study provides a more complete empirical understanding of that important, yet under-researched, missing link. Second, the paper advances our theoretical understanding of the identity of managers and the practice of managerial work in the context of a Big 4 Firm. Following Hinings, Greenwood, and Cooper (1999, p. 151), it is pivotal to understand what management actually means in the context of accounting firms, i.e., "[t]he issue for these firms is recognizing something called 'management' which goes beyond financial." If management is indeed one of the central features of the managed professional business (MPB) (Cooper, Hinings, Greenwood, \& Brown, 1996), we need to theorize the identity of managers and the practice of managerial work in a global Big 4 Firm - a task we undertake in the theoretical contribution of our paper.

\section{Theoretical background}

Identity, careers and the accounting profession

The notions of career and professional identity are hallmarks of accounting firms. A central part of an accountant's career is the charter - hence chartered accountant - that develops via a set development program. Typically, the program involves 3-years of training that include course work and practical activities, after which a professional body will grant the charter to the individual. The professional's role is defined by the acquisition of technical skills, expert knowledge and a professional outlook. The corollary of this understanding is the assumption of the accounting career as the steady and predictable development of professional identity reflecting a continuous improvement of technical expertise that accumulates over time in a linear fashion (see Paisey, Paisey, \& Tarbert, 2007).

Recently, the notion of professional identity has instigated a more subtle approach to the study of individuals' careers in accounting firms (e.g. Gendron \& Spira, 2009; Kosmala \& Herrbach, 2006; Miller, Kurunmäki, \& O'Leary, 2008; Suddaby, Cooper, \& Greenwood, 2007). These approaches share an interest in identity formation processes and technologies of identification that provide the mechanisms through which professional subjectivities are forged (e.g. Anderson-Gough et al., 2001, 2005; Covaleski et al., 1998; Dirsmith et al., 1997; Fogarty, 1992; Grey, 1994, 1998; Pentland, 1993; Power, 1991). Many of these studies draw inspiration from Foucault's (1977) analysis of power, and explore identity as a result of disciplinary regimes that constitute individual subjectivities. These studies focus on analyzing the processes of transformation, the power mechanisms that work through them and the forms of resistance that emerge. Two distinct bodies of literature within this critical stream of research are of particular relevance for our research: first, studies on the disciplining of trainee accountants and, second, research on the identity formation of partners.

\section{The socialization of trainees}

A number of studies (e.g. Anderson-Gough, Grey, \& Robson, 1998; Anderson-Gough et al., 2001, 2005; Coffey, 1994; Grey, 1994, 1998) show how trainees in big accounting firms are disciplined, not only in terms of technical skills but also in terms of conduct in a broad sense. These disciplinary mechanisms are often connected to powerful discursive constructs, such as, "being a professional accountant” (Grey, 1998), “client service” (Anderson-Gough, Grey, \& Robson, 2000) or "career" (Grey, 1994), that have strong regulating effects on the trainees' behavior and attitude. Subtle ways of forming conduct are related to everyday social practices in which the notion of being a "professional" accountant is linked to and made equivalent to specific ways of talking, dressing, behaving and even feeling at the office (Coffey, 1994; Grey, 1994, 1998). For instance, Grey (1994) describes how trainees are expected to be visibly enthusiastic at work. The appropriate and professional accountant is constructed as a people who conduct themselves in a certain way and make sure that this conduct is visible at the office. Disciplinary practices exercise powerful effects on trainees and create disciplined professionals, who tend to behave in accordance with the norms of the firm and the values of the profession (Anderson-Gough et al., 1998, 2000, 2001; Grey, 1994, 1998). In other words, the disciplinary mechanisms imply that individuals are socialized, molded and formed to "fit in". The literature on the sociology of the profession has repeatedly emphasized this aspect of becoming a professional, i.e. that the presentation of professional values is a crucial skill (Abbott, 1988; Coffey, 1994; Freidson, 1994), or, to use Goffman's wording, presentation of the self and impression management are central to becoming a professional (Goffman, 1959; Pentland, 1993). In other words, the early formative years in the career of accountants transform them into performers who are able to act out the script delineating what it means to be a professional convincingly.

The socialization process does not unfold without reluctance, resistance and individual strategizing (e.g. Anderson-Gough et al., 2001; Coffey, 1994). Different management technologies, such as time management devices, constitute one important aspect of the disciplining of novices. These devices range from technologically quite simple "personal planners" (Coffey, 1994) to rather complex time budgeting systems (Anderson-Gough et al., 2001). The time management technologies are described as pervasive and an important aspect of the regulation that is part of the trainee socialization process. In a Foucauldian sense, these devices discipline and normalize the trainees. Yet, trainees are not only subjected to such disciplinary mechanisms, but are also, in the words of Anderson-Gough et al. (2001, p. 100), "actively involved in 'managing' the organizational recording of time to further their career progression". The corollary of this insight is that trainees are not only disciplined into professional conduct; rather, actual conduct is formed through mechanisms of discipline in which both power and resistance, control and agency are part and 
parcel of the same game. Foucault (1982) has described this precarious relationship as the "intransitivity of freedom", i.e. power relations can never be total as the exercise of power relies on the at least partial acceptance of the subject. In other words, disciplinary subjects are always at least partly complicit in their own subjection. Empirical work has provided evidence for this assumption. For instance, Anderson-Gough, Grey, and Robson (2006) have focused on networking of trainees and managers, arguing that young professionals seek out "good" clients and position themselves vis-à-vis influential partners to gain visibility. In the same way, the management technologies of time previously mentioned, such as time-recording practices, are not just something to which trainees are subjected to. They more readily tend to use these systems strategically (Anderson-Gough et al., 2001, p. 100). Yet, despite resistance, the norms, values and rules of the accounting firm studied by Anderson-Gough and her colleagues seem to be presented as quite unambiguous. Although some norms are only accepted reluctantly - such as the norm that trainees are expected to participate in social arrangements (Coffey, 1994, p. 950) - it seems clear to trainees what the norms and the expectations are. According to the literature, trainees tend to live up to these expectations, albeit not necessarily by always internalizing the norms and values.

\section{The identity of partners}

While several studies highlight the techniques of identification and the subjectification practices that shape the identity of trainees, relatively little is known about the identity of partners in accounting firms. One notable exception is the work of Covaleski and colleagues (1998) which focuses on the disciplining techniques that shape the identity of partners. They argue that techniques such as management by objectives and mentoring are, "exemplified techniques aimed at transforming autonomous professionals into business entrepreneurs by duplicating the organization within the individual" (Covaleski et al., 1998, p. 294). They conclude that "control in professional firms occurs in a complex field of power and resistance in which people tend to be both explicitly and unwittingly constituted as corporate clones." (1998, p. 324). Literature analyzing the shift of professional firms towards MPBs has emphasized that professional services firms are increasingly commercialized, rationalized and managerialized (e.g. Cooper \& Robson, 2006; Cooper et al., 1996; Hanlon, 1994). Following from this argument, it has been suggested that partners' identity shifts from that of disciplined professional to a more entrepreneurially minded agent (Greenwood \& Suddaby, 2006; Sikka, 2008). For instance, Gendron and Spira (2009) recounted the imagery used at an Arthur Anderson partner meeting where partners were blatantly depicted as "tigers":

"Worried that increased business competition was eroding profits, some partners argued that Arthur Andersen had to adopt aggressive marketing strategies $\ldots$ at the 1989 partner meeting, the themes were profit and sales. The rock song Eye of the Tiger boomed from speakers, and a live tiger was brought on stage. The new head of the US audit division, Richard Measelle, declared that raising profit would 'require the eyes of a tiger, eyes that seize opportunities, eyes that are focused on the kill. It's the eye of the tiger, it's the thrill of the fight"' (Gendron \& Spira, 2009, quoting Squires et al., 2003, p. 97).

While particularly illustrative, this scene could be repeated at other partner conferences around the globe. In fact, at Sky Accounting (the Big 4 Accounting Firm we introduce and analyze later), there was strong emphasis on the entrepreneurial attitude that was expected of partners. For instance, at the annual 2009 partner conference, Sky's CEO chose to hand badges to his partners that featured (in reference to Taleb's bestselling book, The Black Swan: The Impact of the Highly Improbable) a Black Swan, stating, "I am breeding Black Swans". As we will argue, at Sky Accounting and perhaps in other Big 4 Firms, partners were described as entrepreneurs who run their microbusiness within the larger firm. This supports Gendron and Spira's (2009) claim that partners in large accounting firms are considered managers in charge of individual profit centers. Given the commercialization and diversification of the Big 4, it may be safe to assume that senior staff, and especially partners, are expected to act entrepreneurially and sometimes even breed "black swans" in the pursuit of new business opportunities.

\section{Rites of passage}

While there is a growing body of knowledge about the socialization of young trainees and the identity of partners in large accounting firms, there is a dearth of research exploring the space between trainees and partners. Since the two bodies of knowledge seem to differ in their findings, the question is: how can we understand the transition from disciplined trainee to entrepreneurial partner? Save for a few exceptions (e.g. Dirsmith \& Covaleski, 1985), existing research has by and large overlooked the space of the manager. Dirsmith and Covaleski's early contribution is a rare study of links between different career stages in large accounting firms. They analyzed mentoring as a way of preparing managers to become future partners. Their ethnographic study concluded that being a manager was a difficult step in the career of an accountant: "At the very top of the list of factors that caused the managers to almost leave, and one that was voiced with considerable animation, was '... no handle on your career as a manager'." (1985, p. 164). Rather than explaining the ruptures within the careers of accounting professionals, and the tensions between the practices that constituted these steps, Dirsmith and Covaleski focused on the relative benefits of mentoring. Their narrative emphasized an experience of "learning" and "growing", pointing towards a somehow linear career path from manager to partner.

Our paper addresses the same organizational space, asking how we can understand the journey from trainee accountants who are socialized into the profession to entrepreneurially spirited, business-minded partners. We suggest that this transformation occurs during the period 
of being a manager. Because of its transformative power, this phase can be described as a "rite of passage". Interestingly, both Anderson-Gough et al. (2001, p. 117) and Dirsmith et al. (1997, p. 18) mention the notion of "rite de passage" in their descriptions of career steps in accounting firms. Surprisingly, they do not explicate the rich meaning of the notion, nor do they refer to the anthropologist Arnold van Gennep, who coined the phrase at the beginning of the twentieth century (van Gennep, 1960). Drawing on numerous examples from anthropological research, van Gennep argues that passages in social life from one stage, group, territory, etc. to another - are often accompanied by elaborate rituals he analyzed as rites of passage. Van Gennep (1960, p.11) differentiated between three analytically distinct phases that structure rites of passage: separation, transition and incorporation. Turner's $(1967,1974)$ analysis of rites of passage follow this analytical strategy. He argued that the individuals who are about to go through a rite of passage will initially be separated socially and spatially from the environment they are accustomed to. The separation implies the escape from established social conventions. Second, these individuals experience a liminal space in which the rite of passage exercises its transformative power (see also Czarniawska \& Mazza, 2003). Turner describes liminality as anti-structure in which previously established notions of time and space are deconstructed and the individual feels disoriented and confused. Social ties that normally structure experience are cut off, and a set of new, emotionally intensive bonds are formed with agents of the rite of passage. In the third step - when the limen, or threshold, is passed the individuals exit the socially and spatially separate sphere of the passage and are reintegrated into the group, usually at higher status.

In a critical discussion of van Gennep's and Turner's conceptualization, Bourdieu (1991) argues that their descriptive approach obstructs the point that rites function as powerful means of consecration and legitimation in society. He states that the rites of passage represent an arbitrary yet legitimate boundary between two groups. Rites of passage are tolerated, lawful transgressions of that arbitrary boundary. They represent the line that divides before and after as lawful, masking its arbitrariness. Their most important social function is to institutionalize the difference between those who have been through the passage, and those who have not transgressed the boundary (yet). They consecrate the boundary, naturalize its opposite categories and institutionalize them as naturally different. Doing so, the rite engenders social dichotomies (male/female; member/non-member; insider/outsider, etc.) that structure and stabilize social order. Bourdieu refers to this function as "social magic"; the rite of passage creates a social difference where there was none before. To illustrate his point, Bourdieu (1991) gives the example of the last person to pass an exam and the first person to fail it. The difference between them might be minuscule, yet the effect on their self-perception and perception by others is significant and likely to impact their future career paths. In this case, the rite naturalizes a particular vision of social division (Bourdieu, 1991). Making the difference visible and known ensures that it is recognized by others.
Herein lies the power of rites of passage: they are visible representations of a transformation providing a publicly intelligible account of those who endure them. In the words of Bourdieu (1991, p. 119), rites are powerful because they, "act on reality by acting on its representation." Rites of passage make a social division visible and legitimate, and hence ensure that the representations others hold of the individual that endures the rites changes and is accepted.

Changing others' perception of the self is inextricably linked to the transformation of a subject's identity. This metamorphosis creates a cohesive group (those who passed) out of the heterogeneous mix that the group might have represented prior to the experience of this rite of passage. Emerging at the other end of the rite, their identity has been transformed because others who have not undergone the rite have a different representation of those who went through it. Hence, observers will change their behavior towards those who emerged from the passage. Moreover, the person who experienced the rite will have an altered self-image. The anti-structuring that characterizes rites of passage breaks up established patterns and reassembles an individual's subjectivity differently. Consequently, rites give rise to new forms of subjectivity by disciplining individuals and forcing a new self-image upon them. In this sense, rites reinforce the old Greek dictum, "become who you are" (Bourdieu, 1991, p. 122) and command that the subject, "realizes its potential". Experiencing the rites of passage creates pressure on individuals to act in a certain way. They feel a new set of obligations that they have to live up to from now on. They will have to sacrifice certain things in order to "become who they are". The rites give their existence meaning and purpose - but not necessarily the meaning and purpose they have chosen. Rather, the world separated by the passage demands a life according to a script that has been written elsewhere. Thus, a rite of passage is the technology of identification, or in the words of Bourdieu, "[...] it signifies to someone what his identity is, but in a way that both expresses it to him and imposes it on him by expressing it in front of everyone (...) and thus informing him in an authoritative manner of what he is and what he must be" (1991, p. 121). A rite usually elevates one's social position; but once individuals arrive on the other side of the passage, their field of potential action is limited and structured by the role they are expected to play. In this sense, the rite of passage is also a guarantee that individuals remain on the other side and cannot return to their prior status. The rite cuts the masses off from these individuals and elevates their standing, but it also cuts these individuals off from the masses, and by extension, their past sociality and history. Therein lies the inherently conservative aspect of rites of passage. They reinforce a collective belief in an institutionalized difference that reproduces itself through the individuals that go through them. The authority bestowed on the person who passes is merely a borrowed one as power ultimately rests with the institution that produces another partner, another professor, another graduate, etc. only to reproduce itself. Bourdieu puts it succinctly when he writes, "The veritable miracle produced by acts of institution lies undoubtedly in the fact that they manage to 
Table 1

Breakdown of ethnographic observations at Sky Accounting.

\begin{tabular}{lllll}
\hline Formal meetings & Planning sessions & Site visits to clients & Workplace observations/shadowing & Other internal gatherings \\
\hline $15 \mathrm{~h}$ & $8 \mathrm{~h}$ & $16 \mathrm{~h}$ & $40 \mathrm{~h}$ & $25 \mathrm{~h}$ \\
\hline
\end{tabular}

make consecrated individuals believe that their existence is justified, that their existence serves a purpose" (1991, p. 126).

In summary, the important transformation that occurs in the organizational space between trainees and partners can be analyzed as a rite of passage, a phase of transition between two states. In line with Turner, this is a dynamic space, "a process, a becoming [...] and a transformation" (1967, p. 94). Professional accountants are not born as partners; rather, partners are forged out of what is usually referred to as "partner material" and this material has to be shaped into form. The practices that discipline junior accountants do not explain how this shaping takes place. It is our suspicion that the transformation unfolds in the liminal space of the manager. Before analyzing how this transformation took place at Sky Accounting, an account of the methodology that informed our empirical research is presented in the section below.

\section{Methodology and research context}

The empirical research that forms the main basis of our study was conducted between January 2005 and September 2006. ${ }^{1}$ Collaboration with Sky Accounting on qualitative research continues to date. In our data analysis, we have also drawn on material gathered from this ongoing collaboration. Given the research interest in practices of managing and the identity of managers, an ethnographic approach was deemed an appropriate research methodology (Pentland, 1993; Power, 1991). It allows researchers to focus on the concrete and lived reality of organizational members (Garfinkel, 1967) by using data from settings such as meetings, informal gatherings, client conversations and other events.

The analysis presented below is part of a wider study focusing on the retention of talented female staff (see Kornberger et al., 2010). The study focused on the manager level in the organization as this is where, proportionally, the highest number of females left the organization. Hence, we were interested in what was happening at this career stage. While gender remained an important aspect of our research, the question around the practice of managing and the identity of the manager emerged as increasingly interesting subject area. In other words, we realized that while we studied how the gendering of the organization occurred at the level of the manager, we implicitly had researched management as an important institutionalized practice within the Big 4 Firm being analyzed. Whereas most of the data derives from interaction with female managers, organizational members from other levels of the organizational hierarchy were also interviewed and

\footnotetext{
${ }^{1}$ We would like to acknowledge the contribution of Anne Ross-Smith in the conceptualization of our project and the first round of data collection.
}

observed, aiding us in contextualizing our perspectives on the practice of managing. ${ }^{2}$

The data gathering process included four sources of empirical materials. First, Sky Accounting's website, newsletters and other publicly accessible material were analyzed. Additionally, the research team enjoyed access to confidential internal documents, including employee satisfaction surveys conducted by the HR department, performance reports, change management strategies, exit surveys and employment statistics. These sources provided invaluable background knowledge that informed our further data collection and analysis. Second, the research team engaged in unobtrusive on-site observation. We participated in meetings and planning sessions, in site visits to clients and in other internal gatherings. We took notes during our observations and added them to a growing database that allowed us to reconstruct some of the minute details of what the practice of managing actually entailed. Altogether, the research team spent approximately $100 \mathrm{~h}$ at Sky Accounting. Table 1, below, gives a detailed breakdown of the ethnographic data collection.

Third, observations and informal conversations were supplemented by semi-structured interviews with 17 employees from different divisions of the organization, and included partners, directors and managers. A snowballing technique (Biernacki \& Waldorf, 1981) to recruit interviewees from different levels and divisions within the organization was used. Interviews lasted between 45 and $90 \mathrm{~min}$. All interviews were recorded with a digital device and transcribed. Apart from personal questions revolving around issues such as position, career goals, working hours and formal job descriptions, we used the following questions as the semi-structured interview guide that informed our conversations:

- What are your main tasks and responsibilities as a manager?

- What work really matters? What seems to be valued most?

- What skills are most needed? What is recognized as competence?

- How and when do you learn those skills? How do you learn being a manager?

- What does the organization reward? How do you get promoted?

- How do you manage your staff, your relationship with senior partners and with clients?

Fourth, once the research team gained familiarity with Sky employees, we asked organizational members for permission to shadow them. Seven organizational members

\footnotetext{
2 To protect the confidentiality of the interviewees and Sky Accounting, country-specific information is not provided.
} 
agreed, and we shadowed each of them for one working day. All observed members were either managers or directors. Attendance of meetings and client site visits were possible only when the organizational members felt that confidentiality would not be breached. Everyday practices could be observed and combined with accompanying informal conversations that occurred during shadowing; they provided valuable insights into the practices of managing. The atmosphere during shadowing was generally relaxed and staff members revealed many insider stories that they might not have recounted if a digital recorder had been used. In these situations, the researchers took field notes and transcribed the most important points straight after the observations into a database.

Data was analyzed by categorizing it according to key themes that were a combination of theoretically predefined concepts and inductively generated notions emerging from our data. With the aid of the qualitative data analysis package, NVivo, the data was analyzed by working through all transcripts searching for key themes and concepts derived from our theoretical interest in management practices and identity. The codes we deployed included practice, power, identity, gender, values, culture, learning and others such as visibility, promotion, game playing, and performance that emerged from our data analysis. The process was iterative as we moved back and forth between our data, interpretations and theoretical concepts until our narrative emerged. In presenting our data, we have chosen excerpts from interviews, experiences and observations that illustrate the findings.

From mid 2009 until May 2010, a second round of interviews with Sky Accounting senior executives was initiated. As part of the project, 12 interviews with senior executives were conducted, including the CEO (who was interviewed twice), the COO, the CMO, the heads of the audit division, forensics, data analytics and others who jointly constituted the leadership team of Sky. The project focused on what senior management perceived as its biggest challenges. The topic of innovation was quickly identified as most pressing concern. In open interviews, the conversations revolved around how to manage a balance between control and innovation (echoing March's (1991) elaborations on exploration and exploitation). The interviews lasted between 45 and $90 \mathrm{~min}$. Again, all interviews were digitally recorded and professionally transcribed. The data was relevant to our study because it implicitly and explicitly framed what those in power expect from managers striving for partnership. While our data does not allow us to comment extensively on the practice of being a partner, it does illustrate how being a partner is discursively framed by senior management. In this respect, the follow-up interviews provided an interesting complementary perspective to our initial research.

Reflecting on the limitations of our data collection is important. First, because the project was linked to Sky's mission to create the best professional workplace for women, it focused initially on female organizational members. Clearly, the gendering of the organization happened at the manager level, where the male/female ratio was approximately equal (44\% of all managers were female, while $56 \%$ were male), but a disproportionate number of females left the firm during their time as manager. At the director, level a dramatic drop occurred, with only $23 \%$ of all directors being female (source: internal statistics provided by Sky Accounting, 2005). This statistic remained roughly the same between 2001 and 2008 (the first and last date we accessed data from Sky's HR team). Seemingly, this step on the career ladder of being a manager wrote women out of the organization. Examination of the experiences of being a manager revealed the power effects of this rite of passage. Hence, although initially unintended, the focus on female managers brings the subject of our research into sharper focus. Since an open and grounded approach to theory development was conducted in which the empirical material informs the theoretical reflection and vice versa, the shift from the initial focus on gender to interviews with senior executives about their expectations of future partners reflects the journey of the research team.

Second, our study focused on managers. We did not follow trainees through their careers to managers and partners. Hence, we do not offer an analysis comparing the differences between trainee, manager, and partner identity. This would have only been possible if we had conducted a longitudinal study that followed individuals though the different stages of their careers and that analyzed the changes in their identities. Clearly, our data does not allow us to tell such a story. What our ethnography does allow us to tell though is how managers made sense of their past experience as trainees, and how they narrated the differences and ruptures they experienced on their journeys. Our methodology is well-suited to study these experiences and provides an analysis of their impact on identity, power and work practices. While it is important to acknowledge this limitation of our study, we benefit from previous research on the identity of trainees and partners, using these literatures as framing device to contextualize our findings.

Third, during the data-gathering phase, it seems that organizational members spoke remarkably frankly in informal settings but did not repeat the same opinions in front of a tape recorder. Despite assurance that interviewee comments would remain confidential, organizational members might have feared retribution, which is in itself an interesting finding. From a methodological point of view, this directs attention to the fact that every interview is always also an opportunity for identity work for the interviewee. Especially senior executives who have enjoyed extensive media training and often represent their firm vis-à-vis outsiders are skilled storytellers. Hence, the importance of data gathered through unobtrusive observation, informal conversation and shadowing cannot be overemphasized.

\section{An ethnography of the space of the manager}

While the concept of rites of passage is an important tool that underpins our analysis, our narrative does not follow the neat three-step logic suggested by van Gennep and Turner. Unfortunately, empirics are messier. Our account is a detailed ethnography of the passage that forms the space of the manager and focuses on how a particular vision of 
social division was naturalized, structured management practice and transformed the identity of managers. Our narrative is organized as follows. First, we will explain how Sky Accounting's senior management framed partnership as entrepreneurial activity. Then we will describe the rite of passage that shaped the identity of managers. Third, we will provide a detailed ethnographic account of the everyday practices of this transitional space and how managers experience it. Fourth, we will focus on the reshaped identity of managers as they find themselves managing a complex network of clients, partners, and juniors. Finally, we will analyze the crucial skills that enable managers to do their jobs, including the ability to perform (in a Goffmanian sense), to play games and to engage in politicking. Once these three Ps have been mastered, the manager has passed the transitional space and is on track to add a fourth and final " $\mathrm{p}$ " to his (less often her) career: partnership.

\section{"Breeding Black Swans": partners and entrepreneurship at} Sky Accounting

The interviews conducted with members of Sky's senior management team left little doubt that they expected partners in the firm to act as entrepreneurs. Sky Accounting had broken up its traditional service line structure into a more granular organization consisting of more than 65 internal clusters and 150 external market segments. As one senior strategist explained, this granular structure provided

“... lots of room for people to play, lots of room for people to make their mark. [...] We've changed the way we manage the organization, from an innovation point of view all we did was we gave people a lot of freedom. We gave people a process and a mechanism by which to kind of succeed or fail to get money or not get money and let it run" (Gregory, interview).

Partners, defined as "owners" of clusters and corresponding market segments, were in charge of their own strategy development. Sky's CEO stressed in an interview that strategic decisions were made locally at cluster level. The task of leadership was reduced to setting up a structure in which partners could innovate. As a senior strategist explained, "They [local cluster leaders] are doing strategy. We are doing architecture. [...] we've created an architecture for strategy to emerge" (Gregory, interview).

Sky's CEO expressed strong disdain for centralized planning and top-down control, arguing that the collapse of Arthur Andersen and the GFC were proof enough that the future could not be calculated as a linear extrapolation of the past. Hence, he stated in an interview, that planning was a waste of time. For him, the only way to prepare his organization for a volatile world was to invest in, "smart people that have open minds and constantly reinvent themselves." Asked what he expected from his partners, he summarized eloquently that the, "only assumption we make about our leaders is that they can operate without assumptions." He described the "agile culture" of Sky as a key asset because it allowed people to "move around very quickly". Another senior executive and partner described Sky's culture as a "culture of risk" that encourages people, "who are prepared to take risks and fail. It is far more important to fail and fail fast and fail cheaply than to keep doing the same stuff [...]" (Interview, Christian). Frequently, the notion of "disruptive innovation" was used to describe rapid changes in markets, technology and the work practices that Sky tried to explore and exploit. Accordingly, the CEO expected from his partners, above all, intellectual curiosity and entrepreneurial spirit, including an appetite to learn from others:

“... one of the things that I've said to the executives is I don't want you in my executive if you're not intellectually curious. It's one of the things that I constantly want. I want you to go look for things and so we travel around going to the other firms with one mission only. And that's to steal, to steal from the best" (Sky Accounting CEO, interview).

The metaphor of the black swan (Taleb, 2007) embodied the entrepreneurial drive that Sky expected of its partners. Referring to Taleb's book, The black swan: The impact of the highly improbable, the 2009 partner conference ended with a big projection of a black swan. As mentioned previously, every partner received a sticker with a black swan that read, "I am breeding Black Swans." The idea of partners breeding black swans stands in stark contrast to the professional image of the accountant as the guardian of rationality who should prevent black swans such as Enron or the GFC from occurring. At Sky, the image had transformed. Partners were expected to work independently in their clusters and to develop breakthrough ideas that would contribute to the financial success of the firm. One senior partner expressed the relentless pursuit of growth as follows:

“... Stretch is inherent [in our culture]. One of the mantras that we have is 'never be satisfied'. So you can move from there to there and from there to there and what we then would say is 'well maybe this becomes step one of the next staircase'. Never satisfied. And that as an attitude has filtered through not in the way that we communicate to people in public forums but actually in the way we set goals, the way we measure and the way we got our hardware and software of our organization to support exactly the same philosophy" (Matthew, interview).

In summary, being a partner at Sky was discursively framed as acting entrepreneurially. A considerable amount of autonomy was coupled with pressure to increase revenue. In order to do so, Sky Accounting expected its partners to "steal form the best" and "breed Black Swans". This has interesting implications for our study of managers: how could junior employees become the partners Sky's top management expected to act without assumptions? In the following sections we will explore how this transition occurred in the organizational space of the manager.

"Putting a mountain in front of you": the organizational space of the manager

Walking into any of the nine floors that Sky Accounting occupied in one of the most exclusive office buildings in 
the central business district, one could not help but recognize the organizational hierarchy ossified in the office design. Vast open-plan office spaces with countless workstations stretched across the floors. Devoid of personal belongings, these open office workstations temporarily hosted junior staff and managers. Most desks looked deserted. They provided sterile surfaces for laptop computers and hiding places underneath for small cardboard boxes containing personal belongings.

In stark contrast, the offices of partners were organized in a circle at the center of the round office building. Through semi-transparent glass doors, the partners looked out onto the hot-desking area that stretched in an outer ring around their offices. Viewed from a workstation, the partners' offices symbolized the space of those who were at the center of the organization. The occupants of these offices had made Sky Accounting their home, equipping them with comfortable chairs, big cupboards and shelves to store private belongings. In sharp contrast to the transient feel of the open space, the partners were able to personalize their spaces with family pictures, snapshots of clients and colleagues, books, wall calendars and other mementos from days gone by. Doubtlessly, partners belonged to this place, and this place belonged to them.

The spatial organization of Sky Accounting reflects its social organization (e.g. Kornberger \& Clegg, 2004). The relationship between those who were powerful, permanent settlers and those who were transient was expressed in the spatial dialectic between the center and the periphery. The distinction between the "settlers" and those "in transit" indicated a demarcation between insiders and outsiders. How was the transitory space from outsider to insider organized and experienced? The career step of the manager marked the passage from the organizational periphery to the center. Describing the step of becoming a manager, one of our interviewees stated, "A partner said to me when I first joined, and a really good manager had just left ... 'when you make manager, we put a big mountain in front of you and we want you to climb over it, and it's disappointing that this person left an inch from the top"' (Sarah, manager).

Our interviewee used a spatial metaphor to make sense of the passage, linking it to crossing a mountain - an exhausting, strenuous and potentially dangerous undertaking. Climbing a mountain has interesting parallels to climbing the proverbial organizational ladder. While both are spatial metaphors, the ladder presupposes a linear, regular and predictable aid to move upwards. The mountain, on the other hand, is a challenge that implies using judgment, skill and risk taking. This metaphor captures the key characteristic of the rite de passage and represents a space of transition marking a threshold between two stages. The mountain had to be climbed and conquered to arrive on the other side. Interestingly, the interviewee acknowledged that the mountain was not a naturally occurring phenomenon but had been "put there" by partners. Despite this insight, she did not question the legitimacy of the obstacle, which, although arbitrary, embodied a naturalized social division and was hence legitimized and legitimizing (Bourdieu, 1991). The mountain was not described as too high or steep, nor did our interviewee mention that it was put there without preparing the metaphorical climber appropriately. Rather, the failure to climb was individualized. The person who had "left an inch from the top" did not have the tenacity to climb the mountain, and hence dropped out. The mountain embodied a naturalized threshold and even the partner (who put the mountain there in the first place) seemed to be personally disappointed by the manager's failure. Finally, the metaphor of the mountain that needed to be climbed provided a clue to the expected behavior of the manager. Climbing a mountain requires self-discipline and self-guidance - especially since Sky Accounting did not provide adequate maps for the journey. The journey through the passage rendered visible, and simultaneously developed, the ability of managers to make sense of and navigate unknown and complex territory.

The transitional space experienced as a "mountain to climb" was also characterized by a temporal aspect. To be a manager was not the end of a journey but only part of the trajectory that structured careers at Sky. Until having climbed that mountain and arriving at the position of director, one had to be continuously promoted, or exit the firm; this was an example of the temporal structuring of careers as "up or out". The notion of time that structured career patterns was expressed in the organic metaphor of a growth path. The growth path signified a linear and positive upward movement, as one of our interviewees recounted:

"[You are] told very straight that Sky Accounting is a place where we want people that are going places and getting places. Because we have had people who have said, 'I'm happy to stay at senior level', and they've sort of said, 'no'. Because what happens is when those people stay at that level, they throw out the training, they throw everything out. The structure is very tiered so that everyone will keep moving through; you'll be continually on this growth path. And so the organization is structured that they don't keep people who want to stay at a certain level. Except when they get to that director level. I don't think that's right, but that's how it happens. In a lot of other organizations, people are happy staying at a certain level. But here, you've got to want to be going places, you're working in one of the top four firms, you've got to want to be going. If you don't want to be going, then ... find an exit, yeah" (Nicola, manager).

Our interviewee put strong emphasis on the growth metaphor, and its dark side: if there was no growth and a desire "to be going places", one had to "find an exit". Interrupting the linear career paths at manager level would upset the dynamic of the organization. The hierarchy necessitated and enforced constant movement throughout the organization until employees reached the top. In several respects, the manager level marked the decisive step on that "growth path". As the interviewee argued, directors were not any longer beholden to the "up or out" regime. At director level, the constant quest for growth and self-realization had come to a halt. For managers, on the other hand, time and their careers were plotted along a linear extension that had to signify continuous progress. There was no place to rest or stop. This dynamic was experienced as stressful, as one of our interviewees elaborated: 
"I personally just was kind of overwhelmed by it all [having been promoted to manager], to be honest. It was a huge amount of information - emotional information, all at once and ... it was just like all these people with all this huge drive and passion and they want to become directors, and I'm like we're just managers, can we just be managers for a minute?" (Louise, manager).

At Sky Accounting, employees had to either move up or out; there was no time for standing still or simply "being a manager for a minute". The transitory space of the manager represented a space in which managers could not rest. The interviewee also alluded to the "overwhelming" and "emotional" experience of being a manager. As such, the transitory space shared similarities with the emotionally disturbing "anti-structure" that characterizes rites of passage (Turner, 1974). In fact, as the next section will demonstrate, the transitional space of the manager was experienced as extremely destabilizing and de-structuring by the managers we studied.

\section{In transition - managers' experiences of the liminal space}

The dynamic of "move up or out" forced every employee to either pass through the level of the manager or exit the organization. If managers managed to climb that "mountain in front of you", then they were admitted to the inner sanctum of the organization and could settle, both spatially (with their own place) and temporally (they could remain in the same position; the dynamic of growth and progress was suspended).

How was this transitional space, this passage, experienced by managers? All of the managers interviewed described the level of the manager unequivocally as the "hardest transition". Jane, a manager, explained that the "hardest transition" was from senior analyst to manager, "because a senior [analyst] has been booked, they get booked into the system by their manager, their time is full of individual clients", while managers had to juggle multiple roles, including managing a team of juniors; acting as point of contact for clients; reporting to partners; and ensuring that projects were on track and being delivered on time and on budget. The step from senior analyst to manager marked a shift in focus: rather than working directly on projects, managers managed the work of others. They were sandwiched between junior staff, partners and clients, and had to negotiate the inherent conflicts of interest between these stakeholders. This responsibility put significant stress on managers that came to expression in managers' emotional descriptions of their experiences. For instance, one manager repeated her advice to other colleagues who had just been appointed to the manager role:

"I say to them, when they've just become managers, 'your next 12 months is [sic] going to be a nightmare. It's going to be really tough. This is when you need to talk to people; it's when you need the support. Don't think that you're the only one sinking into a big black hole.' That is what unfortunately happens. ... And for me, I was lucky; it was really only six months that I just thought, what am I doing? I'm sinking. Everything I seemed to touch was not right" (Nicola, interview).

This quote is interesting for several reasons. The interviewee emphasized that entering the organizational space of the manager was a highly emotional, disturbing and unpleasant experience. She compared it to a "nightmare" and to "sinking into a black hole". This experience of stress, confusion and disorientation was shared by virtually all of the managers interviewed. For instance, another interviewee recalled her first months as a manager, "My first three months I was just drowning, I was like, how am I supposed to know this? Who is going to teach me? What am I going to do?" (Louise, manager). Being a manager was experienced as an extremely destabilizing and stressful stage. The metaphors of sinking into a "black hole", "drowning" and "nightmare" as well as statements such as, "getting everything wrong", etc. were reminders of the de-structuring and powerful effects of rites of passage (Turner, 1974). The interviewees' metaphors pointed to an experience of losing control. Interestingly, the feeling of losing control was legitimized when one manager, Nicola, as cited earlier, states during an interview, "That is what unfortunately happens. ... And for me, I was lucky; it was really only six months." In the previous section, we saw how the "mountain to be climbed" was naturalized. Here, we can witness a similar way of making sense; the "nightmare" was simply happening to Nicola and when she actually did manage to get through the situation in less time than expected, she ascribed this fact to luck. This echoes Bourdieu's insight that rites of passage represent a naturalized and, hence, legitimized vision of social division (1991). Even the metaphors that were used to make sense of the rite of passage ("black hole", "mountain", and so on) were borrowed from the vocabulary of nature, masking the fact that the rite was a socially institutionalized practice that acted as a powerful mechanism for social inclusion and exclusion.

The rite of passage also disrupted the notion of a linear career path. Following the managers' own accounts, the transition marked the shift from working in a disciplined space to experiencing a lack of structure (a "black hole") and losing their sense of orientation. They felt that they could no longer build on their past trainee experiences as a guide to future action. Nicola expressed the resulting sense of incompetence as follows, "Everything I seemed to touch was not right". Another manager, Louise, was desperately looking for somebody who could teach her what to do. Instead of steady progression on a professional ladder or a growth path, managers seemed to feel that the ground beneath them had disappeared. Both of the above quotes emphasize the temporality and the transitory nature of the experience. This was particularly clear in Nicola recalling her own advice to newcomers, whom she told that "the next 12 months" will be a nightmare. Even though this time period was not fixed and the precise length of it not known in advance (Nicola herself managed to leave the nightmare-like situation in 6 months), both interviewees recognized that it was a necessarily limited period in which a transition took place (van Gennep, 1960). 
Moreover, even though Louise indicated how lonely she felt in the beginning, her statements also make clear that the experience of liminality is a collective one shared by those who enter the organizational space of the manager. This is why Nicola can repeat her advice to every new manager: "Don't think that you're the only one sinking into a big black hole." This collective and repetitive aspect is characteristic of the rites of passage. Yet, the social dimension of work seemed to have changed for managers. While junior trainees mostly worked in teams of two or more, managers rarely worked directly with other managers. Training sessions and more informal gatherings provided occasions to socialize with fellow managers and share the pain and (less often) pleasures of work. When it came to daily work practices the locus of responsibility was squarely on the individual who was busy managing the communication up to the partner, down to the junior team members, and out to the clients. Most social interaction between managers took place informally and was devoted to letting off steam and exchanging coping strategies. We can conclude that while there was a sense of solidarity amongst managers, their daily work routines individualized them.

The individualizing effects of the rite of passage extended into the private sphere of managers. For instance, in an email conversation, one manager explained how she felt dehumanized:

"I have been working every night until 1am (including this weekend) at a client out by xxx [industrial park] that has gone very, very wrong. I am hoping it will all be over by the end of this week and so maybe I will look and feel human again ... Right now the only thing I am craving is sleep - and a facial. I am paying for late nights and bad diet with bad skin ... (Catherine, manager).

As the manager's dramatic experience attests, the stress of work demanded her total commitment. As result, she was not able to live her normal life as she had literally no time left to see friends or family. The managers inhabited a space in which the social ties they were used to were, if not cut, at least put under pressure. Interviewees commented frequently that the demands of work were hard, if not impossible, to reconcile with social life outside work. In the case of Catherine, whom we quoted above, her normal life pattern was interrupted and de-stabilized, up to a point where she craved a chance to "look and feel human again". One can interpret this deeply emotional statement as an effect of the rite of passage she experienced. Clearly, the rite had destabilized previous social patterns. While it might be too strong an interpretation to argue that the space of the manager was dehumanizing, we certainly found in our research that being a manager included the radical de-structuring of routines and the breaking down of the existing patterns. Managers experienced this radical destabilization as a "black hole" in which they felt they were drowning and they wished to awake from the "nightmare" their work life had turned into. The transition space was not structured through clearly defined rituals; rather, its power effects derived from the lack of structure, the intensive focus on the individual manager, and the strenuous, extended period in which the "mountain in front of you" had to be overcome.
While transitional spaces may always imply the destructuring and destabilization of the taken-for-granted life-world of the person who endures the rite of passage, they also include elements of identity formation. If rites of passage were merely de-structuring, they would not fulfill their role as the technology of identification (Bourdieu, 1991). The question to be asked then, is how did the rite of passage shape the identities of managers?

\section{Everyday practices in the transitional space of the manager}

As the previous section demonstrates, the space of being a manager was experienced as destabilizing and de-structuring. The compass that managers had developed throughout their short careers malfunctioned in the black holes and on the mountains they encountered. What did the new terrain they had to traverse look like? What practices were managers engaged in? Shadowing several managers, we learned about the typical day of a manager. Table 2 provides an illustration of what a typical day involves.

Focusing on the work practices of managers (see Table 2) revealed some interesting insights. Management and its focus on coordination, planning, and controlling has long been understood as the pinnacle of organizational rationality. Our analysis shows that the practice of managing was highly fragmented. Managers had to multi-task, and, on average, did not focus for more than five to ten minutes on any one issue. Many tasks were mundane in nature, such as organizing transport to a client site for a junior staff member. Most of their time was spent troubleshooting and communicating with people. Interruptions were the norm, and lengthy periods of focused work in which professional skills and technical knowledge were applied were the exception. Indeed, we were puzzled by the relative lack of engagement with matters that would require professional knowledge. This was surprising as accounting as a profession claims jurisdiction over expert knowledge to legitimize their privileged status in society (Freidson, 1994). Rather than acting as expert professionals, managers took on responsibility for a whole range of areas, including project management, managing client relationships, working closely with partners and managing junior staff. Their daily practices focused on the smooth functioning of the organization, keeping in touch with a diverse set of actors with divergent interests, including junior staff, clients and partners. Fittingly, a manager described herself as a "hinge" that had to balance these three different, often competing actors. In an interview, she identified communication as the most important skill to accomplish her task:

“I think communication's the most important thing, and just making sure that you set up the structure that people know that, you know, that they've got to elevate issues as they arise and let you know the status and the project of how things are going [...] it's all coming back to communication" (Kylie, manager).

Communication skills were seen as the essence of managing at Sky Accounting. Again, this finding was a notable departure from the self-image of the accounting profession 
Table 2

Ethnographic account of a typical day in a manager's life at Sky Accounting.

\begin{tabular}{|c|c|}
\hline 9:00 am-9:15 am & Travel to client \\
\hline \multirow[t]{8}{*}{ 9:15 am-12:30 pm } & Meet three junior Sky staff on audit team at client offices \\
\hline & Discussions of audit work with team; briefing on progress \\
\hline & Roles played by the manager include: \\
\hline & - Technical role: technical conversations about specific issues \\
\hline & - Nurturing role: socio-emotional support and motivation of staff \\
\hline & - Client role: discussion about how to manage client and obtain data from client \\
\hline & - Coaching role: nurturing, mentoring and training on the job \\
\hline & - Supervising role: correct draft reports and provide feedback; quality control \\
\hline $12: 30 \mathrm{pm}-1: 00 \mathrm{pm}$ & Lunch on way back to office \\
\hline $1: 00 \mathrm{pm}-1: 10 \mathrm{pm}$ & Check emails, organize meetings and plan following days \\
\hline $1: 10 \mathrm{pm}-1: 20 \mathrm{pm}$ & Work on computer, check and write emails, organize meeting notes and plan action list \\
\hline $1: 20 \mathrm{pm}-1: 25 \mathrm{pm}$ & Get a drink; informal chat with IT person on the way \\
\hline $1: 25 \mathrm{pm}-1: 40 \mathrm{pm}$ & Try to call some people but unable to get through; more emails; work on auditing timetable for a project \\
\hline 1:40 pm-1:45 pm & $\begin{array}{l}\text { Informal and spontaneous conversation with colleague about missing files and information; no small talk - it's all } \\
\text { about business }\end{array}$ \\
\hline $1: 45 \mathrm{pm}-1: 55 \mathrm{pm}$ & Back to auditing timetable \\
\hline 1:55 pm-2:00 pm & $\begin{array}{l}\text { Briefing of junior employee over the phone; junior staff should put documents together and meet client in XXX; } \\
\text { conversation mainly revolves around junior staff member not holding a driver's license and hence unable to get to XXX } \\
\text { easily; manager ends up organizing transport for junior staff member }\end{array}$ \\
\hline 2:00 pm-2:03 pm & Arrange meeting with staff members \\
\hline 2:03 pm-2:05 pm & Leave for meeting, which is on the same floor but other side of building \\
\hline 2:05 pm-2:30 pm & $\begin{array}{l}\text { Meeting is about three different projects; much of the conversation is about missing documents and missing } \\
\text { information; some audit-related technical issues are discussed; sign-off procedures are agreed upon; process for } \\
\text { reviews and quality control are discussed in detail }\end{array}$ \\
\hline 2:30 pm-2:35 pm & $\begin{array}{l}\text { Walk back to desk via kitchen to get a cup of tea; spontaneous meeting with two colleagues from HR; friendly small } \\
\text { talk }\end{array}$ \\
\hline 2:35 pm-2:50 pm & Back at desk reviewing reports and sending emails \\
\hline $2: 50 \mathrm{pm}-2: 55 \mathrm{pm}$ & Cell phone rings for first time; caller asks technical, audit-related questions; detailed discussion over phone \\
\hline $2: 55 \mathrm{pm}-3: 00 \mathrm{pm}$ & $\begin{array}{l}\text { Colleague from XXX office calls; discussion of email correspondence with client; discussion about audit client; briefing } \\
\text { of junior staff member }\end{array}$ \\
\hline 3:00 pm-3:15 pm & Review reports making small amendments \\
\hline 3:15 pm-3:17 pm & Call IT support \\
\hline $3: 17 \mathrm{pm}-4: 00 \mathrm{pm}$ & Review reports \\
\hline 4:00 pm-5:00 pm & $\begin{array}{l}\text { Resource meeting with HR; conversation revolves around planning time; booking junior staff; and checking on } \\
\text { counselees, especially their billable vs. non-billable time ratio }\end{array}$ \\
\hline 5:00 pm-5:30 pm & Back at desk doing some more review work \\
\hline $5: 30 \mathrm{pm}-6: 00 \mathrm{pm}$ & Social event at Sky: in-house reception for workplace students \\
\hline
\end{tabular}

in which technical expertise seems the pivotal ingredient for a successful career. In fact, at Sky Accounting, soft skills seemed to matter more than technical expertise. In another excerpt, a manager reflected on what skills a manager needed and how these skills were acquired. She, as well as our other interviewees, stressed that formal training was of little use because it focused too much on technical expertise. Rather, the manager identified "soft skills" as crucial:

"Well, the technical stuff you can get on the ground training with people, hopefully before you've been promoted [to manager], because hopefully you want to make sure you've got those skills banked and you know what you're doing beforehand. The softer skills [are] probably the harder thing [...]" (Karen, manager).

As Karen puts it, technical skills should be "banked" before one became a manager. She mentioned that "soft skills" were in fact the hard skills to acquire. The importance of soft skills and communication resulted from the necessity to keep the heterogeneous network of junior staff, clients, and partners in touch with each other. Managers acted as conduits ("hinges") between those different actors, constantly communicating to ensure the flow of information from one party to another.
The following sections will examine in further detail how managers acted as "hinges" between clients, junior staff, and partners. As mentioned above, rites of passage are not only de-structuring spaces, they are also spaces of identity transformation. The managers we interviewed testified to this transformation, describing their identities as embedded in and emerging from a network of junior staff, clients, and partners in which they found themselves entangled. As opposed to an essentialist understanding of identity (such as "the professional" as the essential core of an accountant), the identity of managers emerged out of an interplay of heterogeneous elements within a complex network.

\section{Managing relations with junior staff}

Managing junior staff was a demanding, time-consuming part of the manager's role. One interviewee described this aspect of her work as follows:

“There's your team side, which is making sure you've got your team allocated or resourced, making sure you almost do that 12 months in advance, and making sure you've got the right structure in the team, to make sure that your team members have development as well as 
also meeting the needs; who's best going to complete a certain task for the client [...] And then once you're out in the field, actually nurturing that team. You know, be that - depending on the nature of the team - whether you're almost micro-managing them occasionally, where you need to lead them step by step. But then in other cases you'll realize that a team has a lot of drive, and you let them run the process, and you kind of just come in behind them and gather them and make sure they're going in the right line. [...] And also then reviewing and giving them feedback on their performance. And sometimes that's a really great process to do, and sometimes that's quite tough. But it's an important part of the business because it's probably the step before you move on, where you're still fairly close to the team and you know how everyone's performing and you can give that feedback up the line then to the partners" (Nicola, manager).

The interviewee described the managing of teams as a complex process that included structuring the team and planning resources so that development opportunities for team members and client needs balanced each other. Nurturing and managing the team on site implied "reading the team" and being able to exercise judgment in regards to management style and the most appropriate form of intervention, ranging from micro-managing the team to "[letting] them run the process". Finding out about motivations and providing critical feedback were seen as a crucial part of the job. Finally, the manager saw herself as the conduit between partners and trainees, ensuring the flow of information about performance and talent. Accordingly, a manager's key skill was to be able to judge junior staff in situ, and, in turn, adjust their behavior (e.g. nurturing, controlling, communicating, etc.).

A particularly challenging form of exercising judgment was delegating tasks to junior staff. Managers reported that they found it difficult to delegate and judge when to trust junior staff. One manager, Catherine, explained that she found it, "a sort of difficult thing to let go of all the work" and "put a lot more trust in junior staff". To delegate meant to manage the flow of work and decision-making downstream. Managers had to learn when they should trust and have confidence in their expectations, and when direct control and micro-management was needed. In practice, learning when and whom to trust was achieved through trial and error. Consequently, as one interviewee explains, managers "got burnt" and (sometimes) "surprised" by junior staff (Catherine, manager). Often, the judgment was wrong, resulting in conflict. Indeed, managing conflicts was part of a manager's everyday life. For instance, one manager told the following story:

"I had a senior analyst who came to me and said, 'I want to have exposure to some of the management responsibilities for delivering a piece of work.' I said, 'That's great, this is your chunk of the work, I want you to do this.' ... So a week later I get a phone call from a client standing there saying, 'It's a week later and I've heard nothing from either of you; where are we up to with this?' And I'd assumed that she would have done this piece of work. So I then call her and say, "Where is this, have you done it?' and I also put it in an email because I can see that this is actually going to be a real issue with this staff member - this is the second time she's let me down now. ... I'm just going to micro-manage her because she's obviously not able to deliver" (Karen, interview).

The manager made a wrong initial judgment, and only after the client alerted her, did she realize that the senior analyst did not deliver. Her reaction was to quite literally "zoom in" on the analyst and "micro-manage" her. In this case, the manager took control and responsibility for the delivery process. The manager micro-managed her subordinate in the name of Sky Accounting. She acted on behalf of Sky, ensuring that the firm satisfied the client's needs. There is a second important point in the manager's quote. She was in the process of learning how to manage a sequence of events that would result in what was for her an already predictable outcome. As she confidently argued, the incident "is going to become a real issue". Hence, the manager documented her response in an email to create a paper trail. Obviously, she did so because she assumed that when the final curtain on this episode opened, she would need evidence to prove to a jury not yet formed that she had managed "well". As we will argue, such representations of actions formed a crucial part of what constituted management practice.

Implicitly, a concern with power and its effective exercise surfaced in managers' stories about their work. A practice in which control and power were exercised explicitly was performance management of junior staff. As one of our interviewees acknowledged:

“There's a lot of informal conversation that happen across the management group, talking about how do we give negative feedback, how do we coach someone from being useless and not adding much value to a team or being really poorly motivated to actually becoming a member of the team contributing equally to the other team members, or even better" (Karen, manager).

The manager reflected on informal, shared learning amongst her peers that focused on giving negative feedback, coaching someone who was "useless" and not adding much value, and on increasing the performance of someone who was "really poorly motivated". The above statement indicates that the manager had internalized junior staff's (lack of) performance as the main concern. Implicitly, she had taken the standpoint of Sky Accounting and did not identify any longer with those employees with whom she had shared ranks only 6 months beforehand.

\section{Managing relations with clients}

Managing relationships with clients was described as the second key aspect of the manager's role. One manager, Nicola, explained that coordinating and creating relationship across multiple levels within the client organization, including with the CFO or CEO, was pivotal. Again, this included judgment of relationships, and an understanding of the differences between the layers within the client's 
organization. In other words, managers had to learn that clients represented a complex, stratified, and multi-headed hydra that needed to be treated accordingly.

First, managers had to differentiate between different levels within a client firm. Sky managers adjusted their behavior according to the hierarchical position that the client representative occupied in their organization. Consequently, clients were not always treated as proverbial kings. For instance, on one occasion, one of the authors was present when a manager received a complaint about a report from a client via email. The client outlined in their email that the report was too generic and needed more work to address the particular problem the client experienced more specifically. However, the manager simply ignored the request and replied that she would not make any change to the report. Asked by the researcher why she would not respond to the client's request, she explained that the request came from the head of accounting and not from the CFO. Although she dealt with the head of accounting on a day-to-day basis, she saw the CFO as her client. The head of accounting was someone who should help her get her job done, but she would not argue with him about the perceived quality of her work.

Second, managers had to understand the difference between local and global clients. Some local clients were rather demanding and seemed to be able to influence fee structure and delivery effectively and directly. Their power was based on the fact that they could switch service providers relatively easily and hire either one of the other Big 4 firms or one of the many local mid-tier firms. In one case, a partner churned through four managers within a year, a fact attributed to the local client they worked for. The client was described as exceedingly difficult and demanding. Additional stress resulted from the fact that the client had negotiated low hourly rates that made profitable service delivery nearly impossible. However, the partner did not want to let go of the client and preferred to churn managers. For the manager on the account, this represented a formidable challenge that could imply the end of his or her career at Sky. Global clients, on the other hand, were different. In most cases, the decision to engage Sky Accounting was made elsewhere. Hence, a sour relationship between one of the many country subsidiaries of the client and the local Sky Accounting office would hardly provide a good enough reason for the global head office to change its accounting firm. Consequently, the local client had little direct power and was treated accordingly. Managers had to learn to differentiate and rank their clients along these two dimensions: local and global, on the one hand, and internally within the client organization on the other hand. Thus, the "client" was a complex construct, and learning to map and navigate that complex construct was one of the most challenging parts of a manager's job.

So was managing the day-to-day relationships with clients. As auditors, the Sky teams were seen by most clients as a necessary evil. In one instance, we witnessed a major conflict with a local client organization. A junior accountant who had started work at Sky two weeks previously was verbally abused by a client. He had asked for evidence of a piece of art valued at $\$ 55,000$ in the books, but that could not be located within the organization. The CFO lost patience with the eager junior accountant and his persistence and told him to leave him alone (using that four letter word). The team on site consisting of five junior accountants was shaken by this verbal transgression. The manager had to confront the client and ask him why he had reacted so strongly and abused her staff. After a lengthy discussion, it turned out that the artwork was already paid for but still in the artist's studio. The client's board had approved the purchase but because the artwork consisted of a rather heavy bridge-like structure, the client's facility manager decided to store it in the artist's studio until the company was moving to a new building. Finally, the manager found out that the company had decided to adopt a new corporate identity and a new logo that expressed its vision of "bridging the gap". Hence, the artwork made sense in the CFO's eyes, but for the junior Sky accountants it represented a rather mysterious purchase. For the manager, managing client relationships meant understanding that numbers do not speak for themselves; they have to be interpreted, made sense of, and framed socially.

Finally, clients had an internal dimension within Sky Accounting. They were important vehicles for positioning oneself for promotion. Working for the "right" clients that provided the manager with opportunities to "act the level above" was crucial, as one interviewee explained:

“... you have to demonstrate it on at least one key client in your portfolio, that you have performed the next level on that one client, and then across your other clients to demonstrate that you have got the skills. Because it's not always the opportunity to work at the next level on all of your clients before you get there, 'cause if you're a manager you might have a director above you, and a partner, so often you sort of hit a bit of a road block in front of you so you need to be able to demonstrate that you've got the skill. It's about trying to make sure you can pick the one client that you can do that on, sort of six months before you want to get promoted, and then make sure that you're given various opportunities across the rest of your portfolio" (Kylie, manager).

The manager explicitly referred to using clients to position herself for promotion. The corollary of this insight is that clients made (or broke) careers at Sky Accounting. The key to promotion was the ability to pick a client that would allow one to demonstrate one's talents. In other words, the client became a discursive resource that could be mobilized to position oneself internally. While Anderson-Gough et al. (2000) stress the disciplinary power of the notions of "client" and "client service", our analysis shows that at the manager level, "the client" was a more ambiguous concept with several different facets, not all of which were disciplining in their effects. In fact, managers had to learn how to make sense of clients. The complexity of navigating clients was an important part of being a manager, because not all clients were equal and nor did "client service" signify the same thing at different times. Rather, being a manager included being able to deconstruct the notion of the client as "one" firm, understand its networked nature, and capitalize on the client to further one's careers within Sky Accounting. 
Managing relations with partners

A third important aspect of being a manager included managing partners and taking responsibility for internal affairs at Sky Accounting. According to one interviewee, being a manager included, “... helping run the business here at Sky Accounting. [...] it's the time when you start to get involved in things that need to be done within the firm, whether it's organizing a social function or organizing how we're best going to mentor the guys" (Nicola, manager).

Managers were expected to get involved in managing parts of the organization and show interest in different aspects of the business. During this time, the inner workings of Sky became apparent to managers. They found themselves inside the black box of the organization where negotiations took place and decisions were made. Being inside implied close contact to those who owned Sky Accounting: the partners. Managers said frequently that they spent considerable amounts of time managing their relationships with partners. They had good reasons to do so. First, partners were the de facto brokers of managers' future careers, as one manager explained:

"And you've got to work for the right partners. ... See, if you work for the vociferous partners, the young stars, they will talk about how good you are and they will get you promoted single-handedly" (Sarah, Interview).

Second, the powerful position of partners also created unpredictability for managers. For instance, some partners would use their power to override decisions managers had made months in advance. During an interview a manager gave the example of how one of her juniors did not turn up at work because a partner decided that he needed her that day:

“She didn't turn up [at the client] because a partner had called a meeting with her that morning and the meeting was supposed to go from eight till nine .... and at 11:30 she was still sitting in the office talking to this partner. And I was sitting there saying, hang on, knock, knock, knock aren't you supposed to be in XXX? And she's going oh, oh, oh. ... the partner said, 'Who are you working for?' and then dragged me in and said, 'She's not going to be out at that client today so we have to do something else about it"' (Karen, manager).

Ironically, the planning of the manager (the hallmark of managerial rationality) was overthrown by the partner's spontaneous decision to prioritize his client over the manager's agenda. In other words, next to junior staff and clients, partners created part of the uncertainty and ambiguity that managers struggled to organize.

Third, working with partners also meant understanding one's obligations and sacrificing oneself when necessary. One manager told the story of a client who did not receive a report on time. The partner responsible for the client arranged a meeting with the manager and yelled at her, arguing that it was her responsibility to deliver the report on time. She recounted:

"I had all the documentations and emails to prove that it was not my responsibility. If I had not filed all correspondence there would have been no way to prove that it was not my responsibility. So I showed the evidence to the partner and the account director and they finally accepted the fact that it was not my fault. What did they do? They apologized for yelling at me but they also said that they will have to sacrifice a lamb in the next client meeting - somebody needs to be blamed for the mistake - and that this lamb will be me. So how do you think I felt last Friday? It's a culture of blame here ..." (Karen, manager).

Several managers referred to the organizational culture as a "culture of blame". As the first point of contact for both junior staff and clients, managers often took the blame for mistakes that might have been the partner's responsibility. Managers' coping strategy was to document workflows in order to be able to defend their actions. In an internal meeting, a manager explained the importance of "writing everything down and sending emails after meetings to everybody involved and always filing all email correspondence" so that if anything went wrong one could prove that responsibilities had been discussed and agreed upon. Another manager had a folder on her desktop called "cover my ass". Asked what the folder contained, she replied that it was the documentation folder for all her electronic correspondence that she would need to "cover her ass" in case of a conflict with a partner. This was for good reason. Since it was the managers' task to manage the day-to-day business of the organization, managers were mostly blamed when clients complained, deadlines were not kept or budgets were blown. As the above quote shows, in these cases it was important to be able to produce evidence that one managed the process properly.

The corollary of this insight is that a focus on the process of managing can be interpreted as a tacit confession that outcomes are beyond the control of management. Knowing that playing by the rules and moving step by step does not necessarily lead to the desired outcomes, the manager also knew that documenting that she played by the rules and moved step by step was a way of legitimately accounting for her actions. Managers discovered that documenting their activities was a useful device to protect themselves from those in power. Management, it seems, was not only concerned with actions and decisions, but with the representation of actions and decisions. As will be shown in the next section, being seen to do the right thing may even have been more important than actually doing the right thing.

\section{Performing, playing games, politicking: being a manager}

Managers acted as "hinges" and their identities were constituted relationally in a network composed of clients, partners, and junior staff. The notion of "partner material" was reserved for those who were judged to be able to reach the goal of partnership. "Partner material", however, is an ill-chosen phrase as the judgment whether someone was "partner material" or not rested, ironically, on less material factors, including performing, game playing, and politicking. Eventually, the three Ps would lead to the fourth "P" - partnership. 
Being a manager requires presentation of the self in appropriate forms (Goffman, 1959). It implies understanding the expectations between oneself, the audience, and fellow actors. Thus, managers have to perform by acting, playing, and investing in impression management. The performance of the managers we studied resembled a Goffmanian interpretation of performance. Frequently, managers explained that the presentation of the self, exposure and selling oneself were crucial to succeeding in their careers:

"I think for me it started to become evident even when I was trying to get from senior to manager, and then going again from manager to director - it is all about exposure. If you don't have that exposure, and those who make decisions don't know who you are, they are less inclined to support decisions for promotion, and it was a sort of a realization that, well, if people don't know who I am, how am I going to advance myself through the firm? So, it then became in my eyes very important to make sure that I got involved in certain initiatives that the firm might be bringing up that would give me exposure to the people that I needed to be exposed to. ... I don't think people realize. I think a lot of people think that if they turn up and they do their job, they clock in and they clock off, they get the audit reports signed off, and all of those types of things ... the day-to-day stuff - and if they work hard and meet their deadlines, that they'll get promoted. I think that will only get you so far. That will get you to senior analyst, maybe to manager level, but they have missed that whole thing about not only selling Sky Accounting, but selling yourself, and that's the key" (Sarah, manager).

In this excerpt, the manager argued that exposure and selling oneself were key to advancing at Sky. She stressed the importance of getting involved in projects for the sake of visibility and networking. Hence, managers developed performance skills that enabled them to act symbolically and identify effective stages that offered good visibility. Paradoxically, doing a good job was not enough to progress. Managers had to invest time and effort in activities that looked good, rather than focusing on outcomes. In the manager's quote, it is evident that what counted as performance and what constituted "real" performance did not necessarily coincide. While some actions might actually diminish performance, they may simultaneously enhance the perceived performance of the manager.

This paradoxical situation was created when managers invested more time and effort in the representation of results than in actual results. The manager creating a paper trail of the failure of her junior staff rather than trying to prevent their failure was but one of many examples in which more energy was invested in representation than in attempts to change reality. Since the representation of results and actual results were often hard, if not impossible, to differentiate, we can speculate that it may be a rational strategy for managers to spend resources on representation and impression management that may impact negatively on the overall performance of the organization.
Logically, failure to be promoted was linked to managers' inability to "perform", as one manager related about a colleague who was overlooked in a promotion round:

“... he was a really nice guy and a lot of people looked up to him, but he didn't sort of play the PR game, he didn't put himself in front of the partners saying, you know, 'I'm this achiever, I'm this, I'm that.' He just quietly got on with his job and he produced good work. But, yeah, I think a lot of it's about PR. Yes, you have to really put yourself, you have to sell yourself here so much more. .... And if you're a shy person or someone who's really not interested in going, 'Hey, look how great I am' or that's just not in your character, then it can be a little bit difficult to get on" (Catherine, manager).

Again, good work was not seen to be rewarded; rather, investment in PR and playing the game were key to promotion. The notion of the "fame agenda" was frequently used within Sky to describe the importance of visibility. The "fame agenda" meant that employees had to be known be famous - for something special within the organization. The "fame agenda" unashamedly advertised a culture in which self-promotion was an essential ingredient for success.

A successful performance also implied the right choice of stage and audience. Networking with the "right" people made a big difference, as one manager explained bluntly:

“[...] to be successful in a professional services firm, it's just as important to be able to profile yourself internally ... so networking I think is incredibly important. ...

There is a lot of who you know followed by what you know. What you know is very important, but who you know will make a difference" (Anne, manager).

Managers were expected to be visible and socialize with partners and their network. People referred to "playing the game" on the right stage as key to getting promoted:

"I think in coming here there were certain things that I knew I had to do as soon as I arrived, so I'll just keep my promotion on the June track. Do you see what I mean? So if somebody else arrived here at the same time as me, and didn't get promoted here in June, and I would say that's largely because they didn't play the game well enough. Technically they're as good as me, with clients they're probably as good as me, but just sort of their contribution to the office, so the wider, being seen to be helping with initiatives around the office and things, I think makes a big difference when you go form manager to director" (Sarah, manager).

The interviewee mentioned that one has to be "seen to be helping with initiatives" rather than running initiatives. Again, playing the game and having a "feel for the game" were crucial for manager's performance:

“...the people who get promoted from manager to director quickest are those who see that things change and become aware that they need to play the game or contribute more to the all-round office, rather than just sit there and do a very good, very technical job. It's 
those people who get promoted to director" (Sarah, manager).

The manager stressed the importance of being aware of the rules of the game and how to play it. Playing the game means framing one's actions and representing them in such a way that they count in the game being played. The game being played was not about technical excellence but about being seen and selling oneself. The frequent referral of our interviewees to making things and themselves "visible" is testimony to how important representation was - a reminder of Bourdieu's analysis of rites of passage which suggests that they are only powerful because they are highly visible representations of social order. This had consequences for the identity of managers, as one interviewee elaborated:

"I think it is a combination of making sure that you sell yourself - that you market yourself to the right people, so that those who have the power to make decisions are aware of who you are; showing true dedication and commitment; and a passion, in a way, for what you do, is another; and having something that separates you from the others. But, you have to sell yourself" (Jenny, manager).

The elements of a successful performance included choosing and attracting the right audience, showing dedication and passion, and being different from others. Interestingly, the notion of selling yourself, on the one hand, and being committed and passionate, on the other hand, did not seem to be perceived as contradictory. One explanation would be that those who "climb the mountain in front of them" arrived transformed on the other side of the mountain. Becoming an insider may necessitate that "true dedication" and "selling oneself" lose their mutual exclusiveness.

Finally, the manager-performer realized that organizational reality was inextricably linked to the exercise of power. One interviewee talked about her "discovery of politics" as follows:

“When my partner went to the panel thing, they didn't know who I was. Or one of the people on that panel, the most senior person on that panel, didn't know who I was. And he [my partner] came back and says, 'No, you're not going to get promoted because this person doesn't know who you are,' and I said, 'Well, fair enough.' You know, I've never spoken to him, I guess it reflects on him a little bit, but it also reflects on me quite a lot, you know; never mind. And then some of the others on the panel started asking around about me and finding out what I'd been doing and went back to that person. And I did get promoted. So because I shouldn't have heard that communication that, 'You're not going to get promoted because this person doesn't know who you are,' that was a mistake, and I was told subsequently that was a big mistake, don't tell anybody about that. ... So I guess I've seen that there is that political inside ..." (Sarah, manager).

Sarah's story illustrates the power of senior partners. Because the senior partner on the panel did not know our interviewee, her initial promotion application was not successful. Politics play an important role in the twist that her story takes. Because her partner was able to mobilize her network, she finally received her promotion. Speaking more generally, managers learned that being part of Sky Accounting is inextricably linked to politics. One interviewee realized how important politics were:

"I always thought politics was a dirty word at work, but it's reality, it's reality and it's not, it's not being sneaky. It's just the making sure that, you know, your people who are going to help you go where you need to go [are] aware of you and know what you do. So it's, it's, it's talking about what you've done, your achievements, to the right people" (Nicola, manager).

Politics had become a reality in the manager's world. It was not a "dirty word" but simply expressed the necessity that one's performances have to be seen by the "right" audience.

In summary, presenting oneself as "partner material" included being able to perform, playing the game, and accepting that "politics is not a dirty word". These three Ps - performing, playing, and politicking - added up to the one final "P" of partnership. Maybe surprisingly, technical skills or professional knowledge were not mentioned when our informants spoke of "partner material". More in line with an anthropological analysis of organization, the root metaphor was to "fit into the culture". One interviewee explained that one either dislikes the culture and leaves or one "matures" and "grows into the culture" and becomes a true Sky Accountant:

"Either they'll [juniors] leave the company because they don't like the culture, or they'll mature and they'll grow to the position and say, actually, it's a good life. I mean I'm not always right, but I do have a lot of interaction with partners or directors or whatever, so you see the business from a different perspective from what you see it when you're doing the work and ticking the invoices" (Louise, manager).

At the end of the journey over the mountain that was put in front of the managers, a "good life" awaited them. On that other side one could see the organization from a different perspective - maybe eventually from the inside of one of those offices with semi-transparent glass walls overlooking the big open space filled with transient outsiders eagerly waiting to climb the mountain in front them, a rite of passage most of them will not manage to overcome.

\section{Discussion: identity, power, and practice}

This paper set out to explore the organizational space between junior trainees and partners in a Big 4 Accounting Firm. In order to do so, we conducted an ethnographic study of managers that suggests understanding the career step of the manager as a rite of passage that had two effects: first, our ethnographic narrative suggests that managers' identity had been destabilized; and second, their identity was re-shaped and constituted around a set of skills (performing, playing games, and politicking) that enabled them to navigate the complex network of junior 
staff, partners, and clients. The way managers made sense of this passage can be described as a rite of passage. It is the "big mountain" that has been put in front of them, marking the journey from transitory employee to permanent settler. In the remainder of this paper we will discuss the implications of our findings for the identity of managers, power relations and the practice of managerial work.

\section{Identity of managers}

Our study allows reflection on the notions of time, career, and identity of managers in accounting firms. Previous studies stress the temporality that structures careers. For instance, Anderson-Gough et al. (2001) study the temporal dimensions of professional socialization. Studying the "strategic life-plan" of trainees, Anderson-Gough and her colleagues (2001, p. 117) analyze examinations as rites de passage that were seen as a, "barrier to entry into the occupation (...)". The temporal visioning of a career in a large accounting firm was engendered as a progressive move up in the organizational hierarchy. In this sense, career is understood as an ordering mechanism. Similarly, Grey (1994, p. 495) develops the notion of career as a structuring device, stating, "[i]n contrast to the unintelligibility, chaos and paradoxical nature of social relations in general, career offers at least the potential for the management of the self through 'steps on the ladder' or 'moves in the games"'.

Our analysis shows that beyond the trainee space, the linearity expressed in accounts of career is replaced by a more complex, fragmented experience. The careers of our managers did not reflect a predictable path progressing over levels and steps. Rather, our interviewees experienced a sudden destabilization of their previous identity when they became managers. On paper, the promotion to manager looks like taking another step up the career ladder, but listening to our interviewees, this is a somewhat misleading representation. The linearity invoked by metaphorical ladders and pyramids hides the fact that the experience of the managers who take this step is rather one of sinking and falling - a metaphor signaling a downwards movement rather than an upwards trajectory. Their highly emotional descriptions of the space of the manager as "limbo", "sinking into a black hole", "nightmare" and so on gave clear testimony to the disorientation that they experienced.

In fact, time was not experienced as a linear structuring device. In managers' discursive repertoire, space was more prominent than time. Managers lost the temporal horizon of a traditional linear career and used spatial metaphors to make sense of their organizational reality. Notions such as "put a mountain in front of you", "black hole" and others served as powerful illustrations. Listening to our informants' accounts, careers did not resemble progressive journeys; rather, they were played out in a rite of passage that needed to be traversed to "become who one is".

While we did not study employee identity before and after they were made managers, the accounts of our interviewees provide an interesting testimony of their subjective experiences and the ways managers made sense of their journeys. Theorizing the empirical narrative, we can observe an interesting dynamic at play between de-identification and re-identification. While other researchers have focused on how processes of identification occur in accounting firms (a point repeatedly made in the literature, e.g. Coffey, 1994; Grey, 1994), our story is one of complex interaction between de-identification and re-identification. De-identification surfaced in the managers' accounts of sinking, swimming, and falling, and when they felt that their past experience was no longer a reliable guide for future action. Re-identification occurred when managers acted on behalf of Sky Accounting vis-à-vis clients or more junior staff by supervising, and, if necessary, disciplining them. Moreover, their reflections on their relationships with partners demonstrated some sense of re-identification with Sky - right down to being sacrificed as a scapegoat, which is, after all, a powerful instance of accepting a representational organizational role.

Re-identification impacted on the relation between the manager and the organization. Being a manager did not mean being a disciplined cell within a hierarchy; rather, it meant transforming oneself into a fulcrum able to navigate a complex network, judge the positions of others within the network and ensure a continuous flow of information throughout the network. Managers learned that they were inextricably embedded in a complex network and that their identity depended on the moves of other actors. The client was not a homogenous entity but comprised of multiple personae that played different roles and was equipped with varying powers at different times. Junior staff members became a heterogeneous mix of individuals who needed varying degrees of control - from micro-managing them to letting them run with a project. Partners could make careers, but they could also sacrifice individuals if necessary. To perform, play games and engage in politicking meant understanding the ontology of the network and developing the competencies to work across the network. Hence, managers' identity was not clearly defined around an essence such as technical expertise or standardized professional conduct. Rather, manager identity was accomplished as a result of interactions within the network in which they were embedded.

\section{Power and the space of the manager}

Power plays a crucial role in shaping the manager's identity. The work of Grey $(1994,1998)$ described the link between the trainee's identity and the disciplinary power that works directly on the body of trainees down to a minute level of detail, including controlling their way of signing a document or dressing. This form of power was not what our managers at Sky Accounting experienced. Their experiences of being in "limbo" allude to the fact that they lacked a structuring power that would organize their world on a micro-level. In this sense, the power that managers experienced was distinguished through a lack of discipline. Nobody told managers what to do. Nobody supervised them closely. No surveillance system monitored their actions minutely. This lack of structure resulted in the dramatic experience of an existential horror vacui, which was reflected in the managers' descriptions of their experience in dramatic spatial terms ("sinking", "drowning", etc.). The power relations that constituted their space 
worked through disorientation, including the dissolving of structuring discipline, linear time and spatial order. Power did not categorize and fix things. How, then, can we analytically describe the organizational power relations we observed at Sky?

Foucault (1982) argued that subjects of power are "free" in as far as power can only be exercised over free agents (see also Miller \& Rose, 2008; Rose, 1999). According to Foucault, power does not determine the actions of subjects but structures the space in which possible actions may occur. In his words, the "exercise of power consists in guiding the possibility of conduct and putting in order the possible outcome" (1982, p. 779).The corollary of this insight is that "[p]ower is exercised only over free subjects, and only insofar as they are free. By this we mean individual or collective subjects who are faced with a field of possibilities in which several ways of behaving, several reactions and diverse comportments may be realized" (Foucault, 1982, p. 780). The space of the manager was a field of possibilities of conduct that offered the manager a degree of choice, flexibility, and maybe even freedom. This notion of freedom is reflected in a quote by the senior strategist who claimed that senior management gave their people a lot of freedom. Analytically, this begs the question of how managers exercised power as much as how they were subjects of power.

While several papers (e.g. Lambert \& Pezet, 2010) show how power shapes subjectivities of accountants, our study offers insights into how managers actually exercised power. Our managers realized that politics played a crucial role in their work, e.g. politics is not a dirty word, as one interviewee put it. The manager extended herself in the space of possibilities that was demarcated by the partners, clients, and junior staff. The power relations were not intensive (as may be the case with the trainee experience structured by disciplinary power) but extensive and spread across the network. Managers attached themselves to people, projects, and things. They faced the challenging task of exercising power and control over a field in which contingencies and surprise were the norm. That something undesirable will happen was certain - yet the manager did not know when, where, or how it might happen. For this reason, the managers' strategy was to extend themselves across the network and gain visibility in each of its parts. Presence, it seems, was the best insurance against contingencies that needed a swift response. Empirically, the emphasis on visibility, PR, the "fame agenda", etc. was a manifestation of the important role of representation. Our managers spent a vast amount of time representing actions in the network (in the form of project plans, proposals, reports, etc.) so that other people could make decisions based on their representations. Managers exercised power as they struggled to put forward their representations of the world. They learned that the documentation of the process is a crucial element in the fight over the interpretation and legitimization of outcomes - especially if they are unwelcome.

This exercise of extensive power placed a heavy burden on the managers. As a senior partner quoted above put it, stretch is inherent in our culture. And indeed, managers felt stretched, fragmented, and stressed while they exercised power over the elements of the network, trying to hold it together through constant communication between its elements and coordinate action within it. In order to do so, exercise of extensive power by managers rested in influencing others' space of potential conduct. In this power game, managers were neither passive victims nor omnipotent players. They mastered a series of micro-practices (such as the documentation of partner conversation; micro-managing junior staff; using clients to position themselves, etc.) that made them skilled in navigating the network they found themselves in. Performing, game playing, and, above all, politicking can be interpreted as tactics that help in navigating and mobilizing elements of the network.

\section{Managerial work in a global accounting firm}

According to the core argument of the MPB thesis (see Cooper et al., 1996), in a managed professional business, management becomes the quintessential activity. From the heights of neo-institutional theory, management is conceptualized as the ongoing rationalization and economization of firms. From a micro-perspective (e.g. Pentland, 1993), the question is: how can we describe the practice of managerial work?

Ontologically, Sky managers did not manage a hierarchical organization but navigated a complex network consisting of multiple players with differing and changing degrees of influence. To be sure, managers experienced the power of their superiors (mainly partners). But it does not suffice to describe their organizational reality as a hierarchy because hierarchies also protect less senior staff through rules and regulations (du Gay, 2000). Hierarchy offers an explicit structure in which flows of information upwards and decisions downwards are structured according to rules. Hierarchical rules provide the luxury of stable anchor points - something our managers could not rely on. Neither did managers enjoy stable positions within a hierarchy; all they could rely on were temporary points of perspective from different parts of the moving network. Everything - the (in)actions of junior staff, partners' spontaneous decisions, clients' numbers - everything could feed back, and sometimes bite back. Managers, it seems, where in a constant repair mode to minimize potential damage and to ensure a smooth flow of information across the network.

Epistemologically, in analyzing the practice of managing at Sky Accounting, it became obvious that professional know-how provided a rather limited repertoire to deal with the complexities, ambiguities, and unpredictable contingencies that occurred in the network: technical expertise will get you only that far, to use the words of one of our interviewees. Or as the CEO put it, we have the assumption that our people can act without assumptions. This begs the question: what knowledge did our managers draw on when they reflected about their practice? In order to make sense of and be able to navigate the complex network of clients, partners, and juniors, our managers had to judge their position in relation to that of others. Managers had to understand the perspectivist nature of reality. Rather than looking for a principled answer, every decision had 
to be made sense of in situ. Clients and junior staff were not given stable entities, but rather a moving assemblage that had to be judged according to its potential to cause problems. Problems could come and go without warning, e.g. an audit at a client could escalate into a sizable problem because of an eager trainee, an inpatient client, and an unusual purchase. Hence, judging relations within the network and interpreting rules of the game were crucial skills. As Bourdieu (1991) reminds us, the rules of the game are never written in stone - they have to be imagined as regularities that are contested and negotiated. Micro-managing a junior staff member, creating a paper trail, building informal networks, subscribing to the fame agenda, judging the internal hierarchy of the client and ignoring client requests and other activities were not only moves within the game, but also experiments in bending, and sometimes maybe even breaking the rules of the game. Our managers had to learn to be pragmatists, who, instead of hoping for guiding principles, had to live by rules of thumb that were the costly yet imperfect result of painful past trials and errors. Rules of thumb are reminders of the ambiguous "proverbs of administration" (Simon, 1946) that do not coincide with the smooth epistemological space of professional expertise.

\section{Conclusions and implications for further research}

In this paper we have presented an ethnographic analysis of the organizational space of managers in a Big 4 Accounting Firm. Based on the accounts of the Sky managers studied, they experienced the rite de passage as destabilizing their previous identities. Simultaneously, managers found themselves embedded in a complex network of clients, junior staff, and partners. A set of new practices (performing, playing games, and politicking) enabled them to navigate the complex organizational network. By extension, it also re-shaped their identities. Power relations were extensive in that managers stretched themselves across the network, aiming for visibility to anticipate problems.

In conclusion, our analysis has two implications for further research. First, our narrative gives rise to questions about management as institutionalized practice and its relation to rationality and efficiency. Institutionally, managers have to act as guardians of efficiency; their "visible hand" (Chandler, 1977) is legitimized through its ability to coordinate affairs efficiently. Seen from our managers' perspective, efficiency was an imperfect modus operandi. In fact, efficiency is an unreliable principle in a relational network because many interdependent variables have to be taken into account simultaneously. Efficiency only works as a guiding principle if optimization between means and ends can be calculated. At Sky Accounting, being an efficient client manager might imply being a poor team manager, and being an efficient time manager might mean not taking enough time for activities that generate visibility. In order to do their jobs, managers have to resort to a whole set of activities (performing, playing games, politicking) that are not efficient. To be visible and develop a "fame agenda" might ironically limit the time managers have to accomplish "real" work, diverting their efforts to the representation of success rather than the actual accomplishment of results. This lack of efficiency was not due to some form of bounded rationality that would limit managers' cognitive abilities. Rather, their rationality was framed ontologically by a network and epistemologically by pragmatism, making managers realize that being efficient did not equal doing a job efficiently. Performing, playing games, and politicking enabled managers to be seen as efficient; but, ironically, these very activities may take up time and resources that make the organization as a whole less equipped to solve problems efficiently.

Therein lies the paradox of managing that future research may address: on the one hand, the manager is the agent of an organization and acts in the name of organizational efficiency. Yet, the practice of managing consists of constant repair work, performing, game playing, and politicking across a complex network. The manager inhabits the impossible space of being the supposedly rational and efficient agent of the organization who has to step outside organizational rationality to make the network flow, repair it, and cope with its fallacies. If management is a congenitally failing operation (Miller \& Rose, 2008), the manager is its tragicomic figure within whom the authority of the rational and efficient system and the need to subvert it in the name of unpredictable contingencies clash. Ironically, this means that it is those who manage organizations that do not act according to the efficiency principle that supposedly guides the organizations they lead. While critical scholars (e.g. Brunsson, 1993; Meyer \& Rowan, 1977) have repeatedly illustrated the gap between rational façade and irrational action as a consequence of organizational and environmental decoupling, our paper nurtures the suspicion that it is management who congenitally reproduces the gap between the rhetoric of efficiency and the reality of performing, playing games, and politicking.

Second, our study emphasizes the importance of ethnographic research methodologies. While Sky Accounting, with its professional status, its well-dressed employees, and its 6-min time regime might seem like the epitome of rationality, the reality of organizing that we observed at the manager level tells a different story. Performance means not being efficient but being seen to act efficiently; what you know is not the only thing worth knowing - who you know becomes more important; and game playing introduces a new dynamic in which unwritten rules trump the (supposedly rational) rules of the organization. Performing, playing games, and politicking added a new dimension to the organization that cannot be described following the logic of an economic rationality. The homo oeconomicus makes bad partner material, indeed. Yet accounting firms represent bastions of rationality in our society: they asses, they evaluate, they audit, and they manage risk. We can only speculate about the moral dilemma that opened up between the encouragement at Sky Accounting to steal from the best, and breed black swans, on the one hand, and the expectations of diligence, predictability, and accuracy from clients and other stakeholders on the other. Further studies on the anthropology of managers (and partners) who act as providers of rationality and hence legitimacy to large parts of society promise 
practically relevant and theoretically surprising results. Authoritative accounts of Wall Street such as, Liquidated: An ethnography of Wall Street (2009), by former business analyst and now academic anthropologist Karen Ho, and Fool's gold (2010), by trained anthropologist and now senior editor at the FT, Gillian Tett, might provide guidance for such a political anthropology of our economic (dis)order, and those forces that produce it.

\section{Acknowledgments}

We would like to thank David Cooper and the three anonymous reviewers for their valuable criticisms and guidance throughout the review process. We would also like to thank Anne Ross-Smith, Joanne Martin, Chris Carter and Frank Mueller who contributed to the development of this paper.

\section{References}

Abbott, A. (1988). The system of professions. Chicago: Chicago University Press.

Anderson-Gough, F., Grey, C., \& Robson, K. (1998). "Work hard, play hard": An analysis of organizational cliché in two accountancy practices. Organization, 5(4), 565-592.

Anderson-Gough, F., Grey, C., \& Robson, K. (2000). In the name of the client: The service ethic in two international accounting firms. Human Relations, 54(9), 1151-1174.

Anderson-Gough, F., Grey, C., \& Robson, K. (2001). Tests of time: Organizational time-reckoning and the making of accountants in two multi-national accounting firms. Accounting, Organizations and Society, 26(2), 99-122.

Anderson-Gough, F., Grey, C., \& Robson, K. (2005). “Helping them to forget. ..": The organizational embedding of gender relations in public audit firms. Accounting, Organizations and Society, 30(5), 469-490.

Anderson-Gough, F., Grey, C., \& Robson, K. (2006). Professionals, networking and the networked professional. In R. Greenwood \& R. Suddaby (Eds.), Research in the sociology of organizations. Professional services firms (Vol. 24, pp. 131-153). Greenwich, CT: JAI Press.

Biernacki, D., \& Waldorf, P. (1981). Snowball sampling: Problems and techniques of chain referral sampling. Sociological Methods and Research, 10(2), 141-163.

Bourdieu, P. (1991). Language and symbolic power. Cambridge: Polity Press.

Brunsson, N. (1993). Ideas and actions: Justification and hypocrisy as alternative to control. Accounting, Organizations and Society, 18(6), 489-506.

Chandler, A. (1977). The visible hand. Cambridge: Belknap Press.

Coffey, A. (1994). "Timing is everything": Graduate accountants, time and organizational commitment. Sociology, 28(4), 943-956.

Cooper, D. J., Hinings, B., Greenwood, R., \& Brown, J. L. (1996). Sedimentation and transformation in organizational change: The case of Canadian law firms. Organization Studies, 17(4), 623-647.

Cooper, D., \& Robson, K. (2006). Accounting, professions and regulation: Locating the sites of professionalization. Accounting, Organizations and Society, 31(4/5), 415-444

Covaleski, M., Dirsmith, M., Heian, J., \& Samuel, S. (1998). The calculated and the avowed: Techniques of discipline and struggles over identity in Big Six public accounting firms. Administrative Science Quarterly, 43, 293-327.

Czarniawska, B., \& Mazza, C. (2003). Consulting as a liminal space. Human Relations, 56(3), 267-290.

Dirsmith, M., \& Covaleski, M. (1985). Informal communications, nonformal communications and mentoring in public accounting firms. Accounting, Organizations and Society, 10(2), 149-169.

Dirsmith, M., Heian, J., \& Covaleski, M. (1997). Structure and agency in an institutionalized setting: The application and social transformation of control in the Big Six. Accounting, Organizations and Society, 22(1), $1-17$.

Du Gay, P. (2000). In praise of bureaucracy: Weber, organization, ethics. London \& Thousand Oaks, CA: SAGE.

Fogarty, T. (1992). Organizational socialization in accounting firms: A theoretical framework and agenda for future research. Accounting,
Organizations and Society, 17(2), 129-149.

Foucault, M. (1977). Discipline and punish. Harmondsworth: Penguin.

Foucault, M. (1982). The subject and power. Critical Inquiry, 8, 777-795.

Freidson, E. (1994). Professionalism reborn: Theory, prophecy and policy. Oxford: Polity Press.

Garfinkel, H. (1967). Studies in ethnomethodology. Englewood Cliffs, NJ: Prentice Hall.

Gendron, Y., \& Spira, L. F. (2009). Identity narratives under threat: A study of former members of Arthur Andersen. Accounting Organizations and Society, 35(3), 275-300.

Goffman, E. (1959). The presentation of self in everyday life. Harmondsworth: Penguin.

Greenwood, R., \& Suddaby, R. (2006). Institutional entrepreneurship in mature fields: The Big Five accounting firms. Academy of Management Journal, 49(1), 27-48.

Grey, C. (1994). Career as a project of the self and labour process discipline. Sociology, 28(2), 479-497.

Grey, C. (1998). On being a professional in a "Big Six" firm. Accounting, Organizations and Society, 23(5/6), 569-587.

Hanlon, G. (1994). The commercialisation of accountancy: Flexible accumulation and the transformation of the service class. Basingstoke: MacMillan.

Hinings, B., Greenwood, R., \& Cooper, D. (1999). The dynamics of change in large accounting firms. In D. Brock, M. Powell, \& C. R. B. Hinings (Eds.), Restructuring the professional organization: Accounting, health care and law (pp. 131-153). London: Routledge.

Ho, K. (2009). Liquidated: An ethnography of Wall Street. Durham, NC: Duke University Press

Kornberger, M., Carter, C., \& Ross-Smith, A. (2010). Changing gender domination in a Big Four accounting firm: Flexibility, performance and client service in practice. Accounting, Organizations and Society, 35(8), 775-791.

Kornberger, M., \& Clegg, S. (2004). Bringing space back in: Organizing the generative building. Organisation Studies, 25(7), 1095-1115.

Kosmala, K., \& Herrbach, O. (2006). The ambivalence of professional Identity: On cynicism and jouissance in audit firms. Human Relations, 59(10), 1392-1428.

Lambert, C., \& Pezet, E. (2010). The making of the management accountant: Becoming the producer of truthful knowledge. Accounting, Organization and Society, 35, 10-30.

March, J. (1991). Exploration and exploitation in organizational learning. Organization Science, 2(1), 71-87.

Meyer, J. W., \& Rowan, B. (1977). Institutionalized organizations: Formal structures as myth and ceremony. American Journal of Sociology, 83(1), 340-363.

Miller, P., Kurunmäki, L., \& O'Leary, T. (2008). Accounting, hybrids and the management of risk. Accounting, Organizations and Society, 33(7/8), 942-967.

Miller, P., \& Rose, N. (2008). Governing the present: Administering economic, social and personal life. London: Polity Press.

Paisey, C., Paisey, N. J., \& Tarbert, H. (2007). Continuing professional development activities of UK accountants in public practice. Accounting Education: An International Journal, 16(4), 379-403.

Pentland, B. (1993). Getting comfortable with the numbers: Auditing and the micro-production of macro-order. Accounting, Organizations and Society, 18(7/8), 605-620.

Power, M. (1991). Educating accountants: Towards a critical ethnography. Accounting, Organizations and Society, 16(4), 333-353.

Rose, N. (1999). Powers of freedom. Reframing political thought. Cambridge: Cambridge University Press.

Sikka, P. (2008). Enterprise culture and accountancy firms: New masters of the universe. Accounting, Auditing and Accountability Journal, 21(2), 268-295.

Simon, H. A. (1946). Proverbs of administration. Public Administration Review, 6(1), 53-67.

Suddaby, R., Cooper, D., \& Greenwood, R. (2007). Transnational regulation of professional services: Governance dynamics of field level organizational change. Accounting, Organizations and Society, 32(4/5), 333-362.

Taleb, N. (2007). The black swan: The impact of the highly improbable. London: Penguin Books.

Tett, G. (2010). Fool's gold. How unrestrained greed corrupted a dream, shattered global markets and unleashed a catastrophe. London: Abacus.

Turner, V. (1967). Betwixt and between: The liminal period in rites de passage. In V. Turner (Ed.), The forest of symbols: Aspects of Ndembu ritual (pp. 93-111). Ithaca, NY: Cornell University Press.

Turner, V. (1974). The ritual process. Harmondsworth: Penguin.

Van Gennep, A. (1960). The rites of passage. London \& New York: Routledge. 